\title{
Desnutrición crónica en escolares: itinerarios de desatención nutricional y programas oficiales en comunidades indígenas de Guerrero, México
}

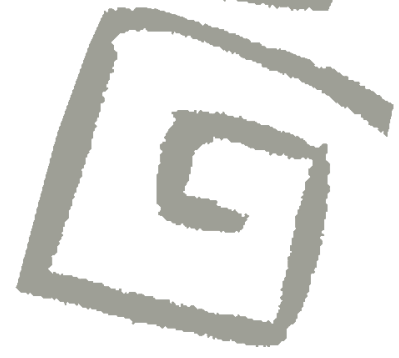

\author{
Chronic undernourishment in school-aged children: \\ itineraries of nutritional neglect and official programs \\ in indigenous communities of Guerrero, Mexico
}

Paul Hersch-Martínez ${ }^{1}$, Julio Pisanty-Alatorre ${ }^{2}$

${ }^{1}$ Médico. Doctor en Ciencias Sociales y Salud. Investigador titular, Programa Actores Sociales de la Flora Medicinal en México, Instituto Nacional de Antropología e Historia (ASFM-INAH), Cuernavaca, Morelos, México. $\bowtie$ (iD)

${ }^{2}$ Médico Cirujano. Auxiliar de investigación, Programa Actores Sociales de la

Flora Medicinal en México, Instituto Nacional de Antropología e Historia (ASFM-INAH), Cuernavaca, Morelos, México. $\bowtie$ iD
RESUMEN En este texto se analizan diversos elementos de la dinámica nutricional de un municipio predominantemente indígena de Guerrero, México, con el propósito de explorar la pertinencia del concepto de itinerarios de desatención nutricional para ampliar la comprensión del daño evitable a la salud. En el marco de un proceso de acompañamiento a la Comisión de Salud de la Coordinadora Regional de Autoridades Comunitarias - Policía Comunitaria, en el transcurso del año 2015, se aplicaron los siguientes recursos metodológicos: a) revisión de programas oficiales mediante consulta de documentos técnicos y entrevistas con personal sanitario; b) obtención de narrativas locales en familias de niños desnutridos, mediante entrevistas y observación participante; c) realización de somatometría en 151 menores en tres escuelas primarias de la región. Se resalta la inadecuación técnica y cultural de los programas oficiales de atención a la desnutrición y la existencia de distintas escalas (individual, familiar, comunitaria, estatal, estructural) y dimensiones (económica, ambiental, cultural, institucional, afectivo-emocional) de desatención, materializadas en altos índices de desnutrición crónica.

PALABRAS CLAVES Salud de Poblaciones Indígenas; Programas y Políticas de Nutrición y Alimentación; Desnutrición; Alimentación Suplementaria; Estado Nutricional; México.

\begin{abstract}
Through the analysis of different elements of the nutritional dynamics in a predominantly indigenous municipality in Guerrero, Mexico, we explore the relevance of the concept of itineraries of nutritional neglect in order to broaden the understanding of avoidable health damage. In the framework of a process of accompaniment of the Health Commission of the Regional Coordination of Community Authorities - Community Police, the following methodological strategies were applied throughout the year 2015: a) a review of official programs by means of the analysis of technical documents and interviews with health personnel; b) the compilation of local narratives from families of undernourished children through interviews and participatory observation; c) the somatometric measurement of 151 children in three elementary schools. We highlight the technical and cultural inadequacy of official nutrition programs and the existence of different scales (individual, familial, community, state, structural) and dimensions (economic, environmental, cultural, institutional, affective-emotional) of neglect, materialized in high rates of chronic undernourishment.
\end{abstract}

KEY WORDS Health of Indigenous Peoples; Nutritional Programs and Policies; Malnutrition; Supplementary Feeding; Nutritional Status; Mexico. 


\section{INTRODUCCIÓN}

La comprensión de los daños evitables a la salud requiere ir más allá del análisis genérico del proceso salud-enfermedadatención y explorar los diversos procesos específicos de desatención que se articulan a diversos niveles (individual, familiar, comunitario, social). El presente trabajo pretende analizar desde esta óptica algunos aspectos de la alimentación, dada su vital importancia para la salud.

El concepto de desatención que enmarca este análisis surge de aproximaciones sucesivas al fenómeno de la enfermedad, considerada durante mucho tiempo al margen de la salud como tal, y conceptualizadas ambas como situaciones dicotómicas, polares, sin matices y estáticas, en un abordaje cuestionado, entre otros, por Laurell, quien señala que ambas nociones son extremos referenciales de un proceso $^{(1)}$. Tomando en cuenta esa perspectiva dialéctica, también se ha expandido el concepto para referirse al proceso salud-enfermedad-atención $n^{(2,3)}$. Sin embargo, tales aproximaciones han prescindido del análisis sobre los fenómenos de desatención, incluyendo su determinación social, sus alcances y dimensiones ${ }^{(4)}$.

A partir de ello, y tomando en cuenta los aportes de Krieger $^{(5)}$ y Breilh ${ }^{(6,7)}$, se ha planteado un modelo en el que el eje saludenfermedad se encuentra estrechamente vinculado al eje atención-desatención en la dinámica de vida de sujetos que se desempeñan en un entorno socioambiental y relacional específico ${ }^{(4,8)}$. El principio básico de esta perspectiva es que los procesos concretos de desatención, a diversa escala, son inherentes a la determinación social de la enfermedad. Es decir, en el daño evitable operan siempre, y de manera subyacente, procesos específicos de desatención, que deben ser identificados para poder incidir en ellos. En esta perspectiva procesal, la contraparte de la salud no es la enfermedad, sino la desatención (Figura 1), que constituye un elemento de referencia desde una aproximación epidemiológica incluyente ${ }^{(4)}$.
El proceso que nos ocupa remite al estrecho vínculo existente entre la alimentación y la salud, y a la magnitud del daño resultante de condiciones de alimentación insuficiente y/o de baja calidad, tanto de aquellas que imperan en la infancia y provocan desnutrición calórico-proteica o anemia ${ }^{(9,10)}$, como las que resultan de la drástica introducción en la dieta de alimentos altamente procesados, que provocan diabetes, hipertensión y síndrome metabólico, que hoy en día tienen una alta prevalencia en México ${ }^{(11,12,13,14,15)}$. Este vínculo demanda entender la alimentación como un proceso sociocultural complejo, y no como mero hecho biológico.

Para que este daño ocurra, los sujetos deben atravesar por diversas oportunidades perdidas de atención nutricional, pues las condiciones de vida, influidas por los procesos grupales (modos de vida) determinan la nutrición del individuo ${ }^{(16)}$. Es decir, a lo largo del ciclo de vida, los sujetos $-y$ las comunidades- atraviesan por situaciones en las que su alimentación puede deteriorarse de diversa manera y grado. Si antes o durante alguna de estas situaciones se recibe una atención adecuada, el proceso tiende a la salud pero, frecuentemente, la dinámica dominante es justamente de desatención, hecho
Calidad del entorno socioambiental

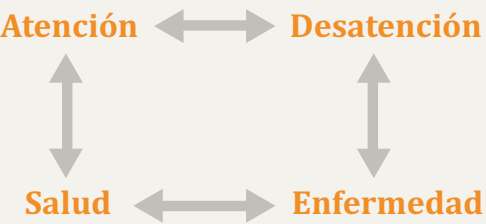

Calidad del sistema de relaciones sociales
Figura 1. Articulación entre los ejes saludenfermedad, atención-desatención, atenciónsalud, desatención-enfermedad y su contexto.

Fuente: Paul Hersch-Martínez ${ }^{(4)}$. 
determinado en gran medida por los efectos combinados de la adscripción de clase, género, etnia, grupo etario, etc. Estas oportunidades perdidas de atención nutricional ocurren en diferentes niveles y escalas, $y$ expresan una gama de factores, desde la política agroalimentaria nacional hasta la falta de detección y/o tratamiento adecuado de las enfermedades nutricionales.

Ahora bien, el concepto de carrera del enfermo y, posteriormente, la figura de los itinerarios diagnósticos y terapéuticos han sido utilizados desde diferentes perspectivas ${ }^{(17,18,19)}$ para el análisis evolutivo de las relaciones entre sujetos que experimentan un problema de salud a lo largo del tiempo y sujetos e instancias -formales e informales-involucrados en ese proceso.

Twaddle señala al respecto que:

...la secuencia de decisiones que constituye una carrera del enfermo tiene lugar, para cualquier individuo, en contextos específicos, en interacción con otras personas que, de acuerdo con su valoración del problema y considerando sus propias necesidades y las oportunidades de vías de acción disponibles, aplican las normas sociales de su grupo particular y marcan expectativas de comportamiento. [Traducción del original: The sequence of decisions that constitute a sicknesscareer takes place for any individual in specific settings in interaction with other people, who in accordance with their assessment of the problem and taking intoaccount their own needs and the opportunities for alternative courses of action which are available, apply the social norms of their particular group and set expectations for behavior]. (Destacados del original) $^{(20)}$

De igual manera, Pescossolido ha señalado la importancia de las redes sociales en la definición de la carrera del enfermo ${ }^{(21)}$.

A pesar de las notables diferencias entre las perspectivas teóricas sobre los itinerarios diagnósticos y terapéuticos, estas tienen en común que se centran en el análisis de las decisiones de un individuo/sujeto dentro de las posibilidades disponibles, valorando superficialmente los factores que determinan dicha disponibilidad. En el presente trabajo se recurre a la figura del itinerario porque remite al paso por diversas instancias o escenarios, pero el foco se coloca en el análisis de la desatención, en este caso nutricional, destacando procesos soslayados e invisibilizados que generan sistemáticamente daños evitables.

La propuesta de itinerarios de desatención nutricional como herramienta de análisis del daño evitable ${ }^{(4)}$ remite a otras experiencias, tales como las auditorías de fallecimientos de menores de un año llevadas a cabo por Serra y colaboradores en los años setenta y ochenta en Costa Rica, que buscaban reconstruir los pasos consecutivos que llevaron a la defunción con el fin de distinguir si se trataba o no de una muerte evitable ${ }^{(22)}$; o el "método de detección de eslabones críticos" planteado por Núñez-Urquiza ${ }^{(23)}$ para evitar la muerte materna, si bien este último se refiere exclusivamente a las interacciones entre pacientes y personal sanitario. De igual manera, el énfasis en los procesos articulados de atención-desatención ${ }^{(4)}$ ha sido ya retomado de manera aplicativa para analizar los distintos factores que llevan en un determinado trayecto a la muerte materna en el contexto mexicano ${ }^{(24)}$.

\section{METODOLOGÍA}

Este trabajo forma parte de un proceso de acompañamiento a la Comisión de Salud de la Coordinadora Regional de Autoridades Comunitarias-Policía Comunitaria (CRAC-PC), sistema autonómico de seguridad y justicia, generado hace 20 años en comunidades indígenas del estado de Guerrero, y que recientemente expandió sus áreas de acción ${ }^{(8,25,26)}$, bajo la premisa de que la seguridad y justicia se encuentran en estrecha relación con las condiciones de salud, producción, educación y comunicación de los colectivos sociales.

El estudio se llevó a cabo en comunidades me'phaa, na savi y mestizas de cuatro localidades del municipio de San Luis Acatlán y en una del municipio de Iliatenco, en la región 
de la Costa Chica-Montaña de Guerrero. Las comunidades se ubican en dos sub-regiones: una zona baja, cercana a la cabecera municipal, con tierras relativamente planas y fértiles en las que se cultiva principalmente maíz; y una zona alta, en las estribaciones de la Sierra Madre Occidental, con terrenos en pendiente y clima más frío, donde la producción de maíz presenta menores rendimientos y domina el cultivo de café( ${ }^{(27)}$.

Las comunidades fueron: Cuanacaxitlán (na savi) en la parte baja del municipio de San Luis Acatlán; Horcasitas (mestiza), también en su parte baja; Buenavista (na savi) de la zona alta; Pueblo Hidalgo (me'phaa) también en la zona alta y San José Vistahermosa (me'phaa) en la zona alta, municipio de Iliatenco.

Se partió de un abordaje transdisciplinario y de una pluralidad metodológica, subordinados a procesos de apoyo a organizaciones y movimientos sociales, basados en procedimientos dialógicos y de reciprocidad. Dicho abordaje no destaca la legítima dinámica entre disciplinas, sino la subordinación de estas al problema de investigación, que demanda su aporte diferencial y, a su vez, las atraviesa y engarza; es decir, la relevancia se coloca en el problema y no en una determinada disciplina o en su interacción per se $\mathrm{s}^{(28)}$.

El objeto de estudio, los procesos e itinerarios de desatención nutricional, es eminentemente complejo, y demanda por tanto no solo ser estudiado desde diferentes ángulos (médico, antropológico, biológico, sociológico, psicológico, etc.), como lo haría un enfoque multi o interdisciplinario, sino una comprensión integral, una "síntesis de la complejidad" del fenómeno, que borre los límites disciplinarios en función de problemas concretos que demandan respuestas ${ }^{(28,29,30)}$. Como señala Almeida-Filho: "lo conceptual es construido, creado a través de una práctica cotidiana de investigación [...] pero él no sobrevive sino por referencia a los objetos concretos $^{\prime \prime(29)}$. Por tanto, los métodos deben ser elegidos en función de los problemas de estudio, y no viceversa. Más aún, puesto que los procesos de desatención remiten al daño a la salud de sujetos y colectividades concretas, existe un imperativo ético de subordinar la investigación a aquellos procesos y movimientos sociales que buscan precisamente transformar esa realidad.

En ese marco, se conjugaron tres aproximaciones: a) el análisis de diversos elementos de los programas oficiales vigentes de prevención y atención de la malnutrición; b) una aproximación cualitativa, a partir de las percepciones y narrativas de pobladores en comunidades de referencia, y c) una cuantitativa, consistente en la somatometría de escolares en tres escuelas primarias. Estas aproximaciones se compartieron en el seno de la referida Comisión de Salud de la CRAC-PC.

Respecto al análisis de los programas oficiales, se recabaron y analizaron materiales de promoción y documentos técnicos propios de los lineamientos actuales de la Secretaría de Salud de Guerrero y de las políticas federales sobre nutrición. Se entrevistó también a personal aplicado a dichos programas, tanto a nivel operativo (médicos y enfermeras en centros de salud), como en la Jurisdicción Sanitaria No 6 de Guerrero (Ometepec).

En cuanto al componente cualitativo, en el transcurso del año 2015 se detectaron y analizaron itinerarios de desatención nutricional, y se realizaron entrevistas con madres y familiares de niños con desnutrición, así como con informantes clave. También se recabó información en talleres comunitarios sobre nutrición impartidos por nuestro equipo en las comunidades, permitiendo el análisis de narrativas contextualizadas, tal como propone Bibeau ${ }^{(31)}$.

Finalmente, respecto al componente somatométrico, las prácticas se realizaron en cuatro fechas diferentes en los meses de mayo, junio y agosto de 2015, en la escuela Adolfo López Mateos de la comunidad me'phaa de Pueblo Hidalgo y en las escuelas Vicente Guerrero y Patria de la comunidad na savi de Cuanacaxtitlán. La escuela Patria pertenece al sistema de educación bilingüe, y atiende a niños que viven en barrios más alejados de la comunidad, mientras que la Vicente Guerrero se encuentra en el centro de la misma población y atiende a niños de dicha zona. 
Se registró peso, talla y fecha de nacimiento de todos los niños de $5^{\circ}$ grado de primaria que asistieron a la escuela el día de la práctica, al concluirse un taller participativo sobre causas y efectos de la malnutrición impartido por nuestro equipo. Se incorporó el proceso mismo de medición como insumo educativo y de reflexión al interior del grupo, del profesorado y con padres de familia, con quienes se discutieron los resultados del ejercicio.

Se recabaron datos de 96 niños de la escuela Adolfo López Mateos (54 masculinos, 42 femeninos), 25 niños de la Vicente Guerrero (14 masculinos, 11 femeninos) y 30 niños de Patria (15 masculinos, 15 femeninos). Se midieron las relaciones índice de masa corporal (IMC) para edad y de talla para edad, siguiendo los patrones de crecimiento y puntos de corte recomendados por la Organización Mundial de la Salud (OMS) en 2007 para el rango de edad correspondiente, basados en datos del National Center for Health Statistics $(\mathrm{NCHS})^{(32,33)}$.

El rango de edad fue de 9 años y 8 meses hasta 18 años, con el $97 \%$ de los niños entre los 10 y los 13 años con 11 meses. Los datos fueron analizados mediante el programa WHO AnthroPlus para calcular z-scores y generar gráficos. Se compararon los resultados de las escuelas con una curva normal estándar mediante pruebas de $\mathrm{t}$, y posteriormente se realizó un análisis de varianza (ANOVA) con contrastes, pruebas de $\chi^{2}$, reacciones extremas de Moses y pruebas de $t$ para efectuar comparaciones entre niñas y niños.

Es importante aclarar que, al tratarse de un ejercicio de medición inserto en un trabajo educativo y participativo, los resultados arrojados no son, ni pretenden ser, representativos de la población, más allá de la selección de niños estudiados, pues el método de elección de participantes no cumple con los criterios de una muestra estadística representativa, ni tampoco con los de un "muestreo teórico" como ha sido propuesto para la investigación cualitativa ${ }^{(34)}$. Sin embargo, estos resultados permiten un acercamiento a la dinámica nutricional de los escolares en cuestión y también de las familias y comunidades de las que son parte.
La investigación fue sometida a los mecanismos de autorización ética y aprobada por la Coordinación Nacional de Antropología del Instituto Nacional de Antropología e Historia (INAH). Se obtuvo consentimiento informado de los participantes al inicio de las entrevistas y de las mediciones, explicando el propósito y alcance del trabajo y los procedimientos de preservación de la confidencialidad. En la transcripción de los relatos, los nombres de los informantes han sido modificados para preservar su identidad. En el caso de los médicos, omitimos informar la comunidad a la que pertenecía dado que, en varias localidades, hay solo un médico.

\section{RESULTADOS}

A los fines de la exposición, los resultados se organizan en tres apartados basados en los recursos metodológicos ya mencionados, los cuales se encuentran estrechamente relacionados, formando parte de un enfoque metodológico plural orientado a comprender un mismo problema desde distintos ángulos.

\section{Los programas oficiales de atención nutricional}

Los programas gubernamentales de atención nutricional constituyen un referente crucial para que el itinerario de un sujeto particular se defina o concrete como de atención o desatención. Por tanto, analizar los programas desde un punto de vista técnico y cultural es fundamental para comprender los itinerarios de desatención nutricional en la región.

En el municipio de San Luis Acatlán los programas federales más importantes de atención nutricional son implementados a través del programa PROSPERA (antes “Oportunidades"), con la estrategia de Complemento Alimenticio Estrictamente Supervisado (CAES) aplicada por la Jurisdicción Sanitaria de Costa Chica. Estos programas constituyen, a su vez, la piedra angular de la estrategia federal denominada "Cruzada Nacional Contra el Hambre" 
$(\mathrm{CNCH})$. El programa PROSPERA señala la mejora de la nutrición como uno de sus tres objetivos principales (junto con educación y salud) para "coadyuvar a la ruptura del ciclo intergeneracional de la pobreza"(35). Para esto, además de un apoyo monetario, el programa otorga suplementos alimenticios.

La selección de "beneficiarios" de este programa se realiza mediante censos de condiciones socioeconómicas $y$, en principio, los "apoyos" se entregan a las familias de menos ingresos. Para mantener la afiliación al programa, las familias deben cumplir con una serie de co-responsabilidades, incluidas acciones de salud y educativas ${ }^{(35)}$. Se ha señalado la contradicción entre dicha condicionalidad y el enfoque de derechos que nominalmente subyace al programa ${ }^{(36)}$, así como la existencia de problemas importantes en las estrategias de focalización de los programas $^{(37)}$, mientras que la misma focalización ha sido criticada, entre otras cosas, por omitir la problemática de la distribución de la riqueza, fomentar prácticas clientelares, excluir a muchos de los pobres por no cumplir con los criterios formales, y estar acompañada de una reducción total y per cápita del gasto en asistencia social ${ }^{(38,39,40)}$.

El mismo término "beneficiario" tiene una connotación digna de análisis, puesto que además de "beneficio" denota "favor"(41), acepción con la que frecuentemente es interpretado tanto por los funcionarios del programa como por la misma población, hecho por demás coherente en un sector poblacional históricamente sujeto al despojo propio de la colonialidad ${ }^{(42)}$.

Este programa y sus antecesores han entregado suplementos bajo distintos esquemas. Actualmente, se otorga a todos los niños de 6 a 59 meses de edad de las familias beneficiarias. Estos suplementos consisten en una papilla llamada "Nutrisano", destinada a niños de 6 a 12 meses de edad, que proporciona por porción $194 \mathrm{kcal}$ (aproximadamente 20-25\% de los requerimientos calóricos diarios para un niño de dicha edad), adicionada con vitaminas y minerales. Para los niños de 13 a 23 meses de edad, el programa proporciona la "Bebida Láctea Nutrisano", que aporta 131 kcal por porción (aproximadamente 10\% del requerimiento calórico diario), además de vitaminas y minerales. Adicionalmente, a todos los niños de 6 a 59 meses de edad se les otorga "Vita Niño", un suplemento de vitaminas y minerales sin contenido calórico para añadir a algún alimento ${ }^{(43)}$. En resumen, se entrega un complemento calórico para niños de 6 meses a 2 años, y vitaminas y minerales para niños hasta los 5 años. La fundamentación técnica de este esquema no queda explicitada en ninguno de los documentos de los programas en cuestión, hecho cuya relevancia se destaca en la sección de discusión al contrastarlo con los datos existentes sobre las carencias y necesidades dietéticas reales y con las visiones sobre los saberes alimentarios locales.

En entrevistas realizadas al personal sanitario, tanto en centros de salud como en la sede jurisdiccional, se expresa el interrogante de por qué los niños a quienes se da seguimiento no aumentan de peso y talla al ritmo adecuado, a pesar de recibir los suplementos alimenticios y las transferencias monetarias. Esta situación con frecuencia es imputada a la población misma, dando por sentado que no proporciona dichos suplementos a los menores, o lo hace en forma inadecuada.

Ante los índices persistentemente altos de desnutrición en menores de 5 años, la jurisdicción referida implementó la estrategia Complementos Alimenticios Estrictamente Supervisados (CAES), que consiste en que los menores de edad con algún grado de desnutrición que cumplan ciertos criterios, acudan una vez al día junto con un familiar (generalmente la madre) al centro o casa de salud, para consumir los suplementos alimenticios otorgados por el programa bajo supervisión del médico o auxiliar de salud ${ }^{(44)}$. Su asistencia es registrada y la ausencia constituye una "falta" o incumplimiento de su "co-responsabilidad" para el programa, que repercute en una reducción del apoyo monetario recibido bimestralmente.

Quienes ingresan a esta estrategia son los menores de 2 años con cualquier grado de desnutrición aguda o crónica, y los niños de 2 a 5 años con algún grado de desnutrición 
aguda (peso bajo para talla). Este último grupo constituye más del $60 \%$ de los menores que ingresan a la estrategia, según estadísticas proporcionadas por la jurisdicción $^{(45)}$.

De igual manera, algunos entrevistados destacan la tendencia reciente a eliminar el indicador de talla baja para la edad de las estadísticas y objetivos. Rodolfo, quien trabaja en la jurisdicción, comenta al respecto:

\section{Casi todos nuestros niños estaban en talla baja, tenían una secuela de desnutrición crónica. Ahorita, no sé si por estrategias políticas, nos cambian el indicador para valorar el estado nutricional del niño, y ahora es peso para la talla. Nosotros hemos hecho nuestros comentarios: no es un buen indicador, realmente es enmascarar la desnutrición del niño, porque seguimos teniendo talla baja [...] realmente la desnutrición crónica ahí sigue. (Rodolfo, 27/04/2015)}

Cabe destacar que la perspectiva misma de los trabajadores no encuentra un canal eficaz para la retroalimentación endógena de los programas. También es notable la escasa consideración de la cultura alimentaria local en el diseño de los programas y su erosión consecuente, al igual que la ausencia de participación de la población en el diseño de las políticas nutricionales. Tanto quienes las diseñan como quienes las aplican, parten de la premisa, poco verificada, de que son justamente "factores culturales" los que están en el fondo de los problemas nutricionales en la región. Hiram, médico en un centro de salud, explica:

...yo veo que sí hay, yo voy a donde venden, veo que hay piña, hay plátano, hay mucho, entonces ¿por qué sigue habiendo desnutrición? Es porque no les dan de comer. (Hiram, 25/05/2015)

Al respecto, Rodolfo comenta:

Nosotros hemos visto como que cierta renuencia de las señoras a aceptar que el niño tiene que tener sus cinco comidas.
¿Por qué? Porque son hábitos alimentarios de ellos, hay localidades que nomás dan dos comidas, entonces de repente vienes tú y les dices que tienen que ser cinco [...] Entonces, con todas esas costumbres que tiene la gente, de que dan seno materno exclusivo hasta los dos años, veíamos que el niño a partir de los 9 meses empezaba a tener disminución de peso. (Rodolfo, 27/04/2015)

Partiendo de que las causas de la desnutrición son culturales, o educativas, los programas llevan a cabo estrategias para modificar los "hábitos alimentarios". Para ello, frecuentemente se utilizan materiales educativos generados a nivel federal, como el "plato del buen comer", aunque el propio personal detecta y reconoce su inadecuación cultural. Es de señalar el esfuerzo del personal de la jurisdicción sanitaria por proponer un "plato del buen comer costachiquense", aunque en las visitas realizadas a los centros de salud observamos que la mayoría no utilizaba esta propuesta, sino la federal. Este elemento, significativo, se discute más adelante.

\section{Narrativas locales sobre malnutrición}

Las narrativas de madres y familiares de niños con algún grado de desnutrición arrojan varios elementos comunes, incluyendo factores propuestos como causales directos o indirectos del estado nutricional de sus hijos, así como otros que simplemente se entretejen en sus historias.

El primer elemento común es la falta de recursos económicos. Regina, madre de dos niñas con desnutrición crónica, lo expresa:

El doctor me dijo que yo no le daba de comer... dice él que yo no le doy todo, yo le digo: "porque no hay". Cuando hay sí come, pero cuando no hay [...] Porque no tengo dinero [para] comprar todo lo que van a comer. (Regina, Pueblo Hidalgo, 30/07/2015) 
El resultado en la dieta lo expresa Lorena al describir el alimento de su hija de un año y medio de edad el día de la entrevista:

Tortilla con sal [...] No le voy a dar más. Es la tortilla, nomás. (Lorena, Buenavista, 14/02/2016)

Laura, madre de siete hijos, las dos menores con desnutrición, lo expresa así:

\begin{abstract}
Aquí se acostumbran más las tortillas con frijol. Por ejemplo, cuando son muchos en la familia se les da poquito para que alcancen todos, se les dice a sus hijos 'coman poco porque no va a alcanzar' entonces tratan de comer más tortilla que la comida. (Laura, Buenavista, 23/03/2015)
\end{abstract}

Esta carencia está directamente ligada con las actividades productivas de las familias. En la región, los campesinos que tienen tierra disponen de pequeños terrenos de menos de cinco hectáreas para la siembra. Ramón narra:

Ya casi todo [el terreno] está repartido. O sea, como mucho tienen unas tres, cuatro hectáreas, los más grandes. Como nosotros, casi no tenemos, allá en el ejido no tenemos grandes terrenos [...] Porque con un pedacito de terreno no alcanza. Por ejemplo, nomás aquí mi comadre, del terreno de su jefe, ya fueron repartiendo. Quizá a ella le tocaría como unos... -deja que si le tocara todo, todo parejo- quizá le tocaría para un litro, un litro y medio [de maíz]. (Ramón, San José Vistahermosa, 20/06/2015)

Cabe aclarar que en el municipio de San Luis Acatlán se acostumbra sembrar aproximadamente tres litros de maíz por hectárea. Algunas familias, por falta de tierra, pagan la renta de terrenos. Como explica Regina:

...donde sembramos el año pasado pagamos [...] Lo que sembramos nosotras era dos hectáreas. Ahí cobran por hectárea quinientos pesos cada tiempo, cada año que siembra uno. (Regina, Pueblo Hidalgo, 30/07/2015)

Otro común denominador es la insuficiente producción para satisfacer las necesidades de subsistencia. Lorena explica:

...lo que sembramos [de maíz] nos dura como unos seis, siete meses, y ya de ahí empezamos a comprar. Aunque sembremos más, aquí no se da. (Lorena, Buenavista, 14/02/2016)

Esta baja productividad del maíz en la región, carente de mejoras técnicas dirigidas a incrementar rendimientos y calidad de las cosechas, forma parte, a su vez, en su correspondiente dimensión y escala, del contexto de los itinerarios de desatención nutricional(46).

Las familias de las zonas altas donde se siembra café también presentan dificultades económicas importantes. Josefina explica que con la venta de la cosecha anual de café, su familia compra maíz que debe alcanzarles para el resto del año, además de otros productos como frijol y todas las necesidades de la familia.

Uno trata de irla pasando, ahorrar para irla pasando [...] Quién sabe cómo le hacemos acá, pero el chiste es que salimos. (Josefina, San José Vistahermosa, 02/09/2015)

A lo anterior se añade la falta de otras fuentes de ingreso. Explica Irene:

Y luego aquí no dan trabajo, pues, y uno no puede ir a robar pa comer porque así mis papás no me enseñaron. (Irene, Cuanacaxtitlán, 31/08/2015)

Por su parte, Regina comenta:

A veces le voy a ayudar a la señora que vive allá en el centro, le ayudo a lavar sus trastes, ahí me dan, pues [...] Sí me gustaría trabajar, pero como no 
se puede, con quién [se van a] quedar [...] mis hijos. (Regina, Pueblo Hidalgo, 30/07/2015)

Adicionalmente, la productividad se ve afectada por plagas. Ejemplo de ello es San José Vistahermosa, donde -según las narrativas locales- anteriormente se sembraba maíz, hasta que este fue afectado por una enfermedad. Emerenciana narra: "Y es que la plaga, y todo, ya [...] no ha dado, por eso la gente consiguió terreno allá" (20/06/2016), refiriéndose a la organización comunal que adquirió un terreno en la parte más baja, repartido como ejido. En las tierras comunales de San José, las familias comenzaron a sembrar café, hoy perjudicado severamente por la roya, de forma que, según cuenta Josefina, "no hay nada, no hay nada ahora" (02/09/2016). La magnitud de la afectación del café como principal cultivo en la zona alta del municipio forma parte, a su vez, del contexto de los itinerarios de desatención nutricional ${ }^{(47)}$.

La afectación por plagas está íntimamente relacionada con la dinámica ecológica de la región, que afecta la capacidad de conseguir alimentos. En efecto, en todas las comunidades en las que trabajamos, las narrativas apuntan también a una disminución significativa en la disponibilidad de recursos animales y vegetales silvestres, anteriormente complemento importante para la dieta local. Entre las especies animales cuya disminución es mencionada recurrentemente, se encuentran venados, jabalíes, ranas, iguanas, camarones de río e insectos (como las hormigas "chicatanas"). De igual manera, se señala la menor presencia de vegetales silvestres conocidos como quelites (hierbamora, chipile, pápalo, etc.). Entre sus causas, se refiere el uso excesivo de herbicidas y pesticidas, además de la deforestación y el cambio en los patrones de lluvias.

Sumado a lo anterior, las narrativas denotan una importante erosión de la cultura alimentaria local, manifiesta en los cambios de preferencias de alimentos de las generaciones más jóvenes, como sucede con el consumo de quelites. Irma menciona:
Los niños no lo quieren consumir [...] si aquí tengo yo mi hijo que no lo come. Cualquier quelite, no lo come. Ni la guía de calabaza. (Irma, Buenavista, 24/03/2015).

Las razones de esto son múltiples, incluyendo la mayor disponibilidad de productos procesados en las tiendas y su constante promoción $^{(48)}$. A esto se añaden factores institucionales, como lo expresa Laura:

...una señora [...] llevaba chipiles y hierbamora y ahí le echó el "Vita Niño" y que una vocal [del Programa PROSPERA] la regañó bien feo, porque esa comida [local] no se la debía dar a su bebé. (Laura, Buenavista, 23/03/2015).

Otro elemento referido es la ineficacia percibida de los suplementos alimenticios. Al preguntar a Laura si cree que estos le han servido a sus hijas, responde:

...no, porque se fue [acudiendo diario a consumirlos] hasta que cumplió los cinco años, a los cinco años la dejaron, porque a los cinco ya no les dan. (Laura, Buenavista, 23/03/2015).

Es decir, la salida de su hija de la estrategia CAES se da por criterios administrativos y no por una mejoría, a pesar de consumir los suplementos de manera supervisada durante varios años.

Del mismo modo, resaltan ineficiencias e inequidades en la distribución de suplementos, como expone Josefina:

...como estoy yo [asignada a las caravanas de salud de] IMSS-PROSPERA y [en el centro de salud de la Secretaría de Salud] atienden lo de PROSPERA, nada más [...] lo llevo cada mes, nomás me dicen que está desnutrido, no me dan nada para darle al niño, pues, ¿Cómo va a subir así? [Los de la caravana] ya tiene que no han venido [...] casi no vienen muy seguido. Como no estoy ahí [en el centro de salud]; ya que van a caducar 
a mí me dan. Así he visto yo también hasta el suplemento. Apenas me dieron, es la primera vez que me dan desde que nació, me dieron y estoy checando que ya en septiembre va a caducar" (Josefina, San José Vistahermosa, 02/09/2015).

Francisco, médico en la zona, explica:

...aquí lo que hicieron ellos, se me hizo una tontería, porque lo único que hicieron es dividir a la población. Hay una brigada que viene cada vez que sueña, trabaja con ese grupo. Entonces ese grupo tiene Oportunidades, pero para mí, la Secretaría pide que no lo contemple dentro del programa, porque no me corresponde o no tengo yo la obligación con ellos en relación a los talleres ni al complemento alimenticio, entonces yo no tengo esas obligaciones con ellos, y me quedo trabajando con el resto de la población. [...] Pero si, por ejemplo, hay una embarazadita, supongamos, y se complica, ¿quién la tiene que ver? Pues yo. Si es un niño que se enferma, ¿quién lo tiene que ver? Pues yo. Y entonces manejo yo toda la población, pero no tengo compromiso con aquellos, ¿entonces de qué se trata? (Francisco, 24/03/2015)

Otro elemento común referido en las narrativas es la violencia de género. Sobre las relaciones entre varones y mujeres, Aracely menciona:

[Los hombres] no preguntan si la mujer quiere comer algo, que quiere vestirse algo, que qué se le antoja, o algo así, nada. (Aracely, Cuanacaxtitlán, 25/05/2015)

Teniendo esto como telón de fondo, encontramos violencia machista de mayores grados en un $80 \%$ de las familias con hijos con desnutrición. Lorena narra:

Cuando viene [mi marido], pues, toma muy seguido, y es cuando hace bien feo [...] Es que me pega, está borracho y me pega [...] y es muy celoso, también. Luego la gente le dicen chisme, pues, que su mujer sale mucho, y ya, y me pega. (Lorena, Buenavista, 16/02/2016)

Uno de los múltiples y notorios impactos de la violencia de género es la afectación del estado emocional de las mujeres. Al respecto, Laura explica:

\begin{abstract}
Mismo cuando yo pasé, eso pasé: no tengo ganas de comer ni hacer cosas. Cuando tengo mucho de amontonada la ropa, no tengo ganas para lavar luego que [el dolor por los golpes] se sube a mi cabeza, es como si se quemara. (Laura, Buenavista, 23/03/2015).
\end{abstract}

La depresión y la desatención afectivoemocional son, entonces, otros elementos comunes, frecuentemente ligados a la violencia doméstica, pero también a otros factores, como sucede con Irene, madre de una niña de tres años y un niño de un año, ambos desnutridos. Antonieta, madre de Irene, explica que su hija quedó trastornada luego del maltrato del marido:

Habló [su esposo]: “¿Sabe, suegra? Que ahí te la voy a mandar [...], ahorita quedó loca", dice [...] "Es que sacó su ropa, así chirunda [desnuda] andaba en la calle. A fuerza la agarramos con mis amigos, tuvimos que poner su ropa". (Antonieta, Cuanacaxtitlán, 31/08/2015)

También explica que su hija camina desorientada largas distancias con la niña desnutrida. Estos procesos, relativos a la dimensión afectiva-emocional, rara vez reciben atención institucional. Irene, pese a vivir frente al centro de salud, y a la gravedad de su situación, no ha recibido atención psicológica. Lorena, al preguntarle si ha recibido orientación sobre la violencia doméstica, dice:

No. Hasta ahora que me acuerdo, no. Y los hombres se molestan cuando viene alguien así, que oriente de eso. (Lorena, Buenavista, 23/03/2015). 
En contraste, la importancia de la atención afectivo-emocional es planteada por Juana, quien padeció depresión y recibió tratamiento psicológico gestionado por su familia a nivel particular:

...ya que yo mejoré, ya que yo me sentí bien, mis hijos mejoraron. (Juana, Pueblo Hidalgo, 03/09/2015).

Sin embargo, estas situaciones resultan inusuales. Existe también una dimensión de la desatención relacionada con la impartición de justicia, especialmente en relación con la violencia de género, tal como explica Lorena:

Cada vez que yo demando, me encarcelan a mí también. Por eso ya no quiero. Ahora que vino [mi esposo], lo mismo me hizo, me pegó [...] Y cuando me había embarazado, pues, de mi primer niño, yo estaba dispuesta a separarme de él, y ya dijeron los comisarios que si yo lo dejaba, que iban a encarcelar a mis papás. (Lorena, Buenavista, 16/02/2016)
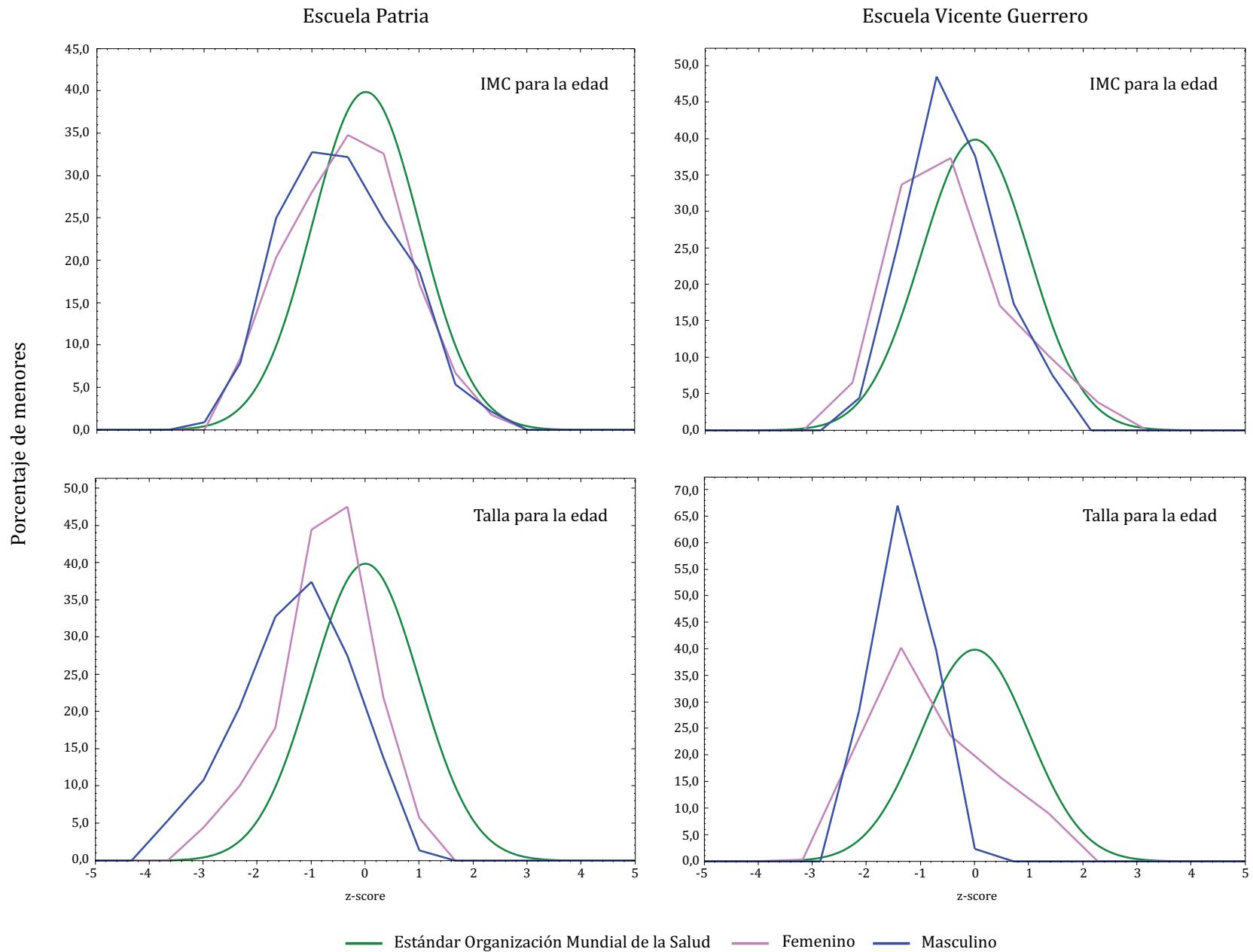

Figura 2. Índice de masa corporal y talla para la edad en niños de quinto grado de las escuelas Patria y Vicente Guerrero, Cuanacaxtitlán, Guerrero. México, 2015.

Fuente: Elaboración propia. 


\section{Elementos cuantitativos: prácticas de somatometría}

Las prácticas de somatometría en escuelas permiten añadir una dimensión más al análisis que se presenta. Los resultados de las escuelas Patria y Vicente Guerrero, de Cuanacaxtitlán, se observan en la Figura 2. En ella, la línea verde representa la curva de crecimiento normal según los estándares de la OMS; la azul, la distribución de valores en los niños y la rosa en las niñas.
La prevalencia de desnutrición crónica (talla baja para la edad) en la escuela Patria fue del $17 \%$, de los cuales el $3 \%$ presenta talla muy baja para la edad (z-score <-3). En cambio, en la escuela Vicente Guerrero la prevalencia fue del $8 \%$ y ninguno de los menores presentó talla muy baja para la edad. Respecto al estado agudo de nutrición (IMC para la edad), si bien en ninguna de las dos escuelas se encontraron niños con desnutrición aguda (z-score $<-2$ ), cabe resaltar que el z-score promedio poblacional fue de $-0,38$ para la escuela Patria y de
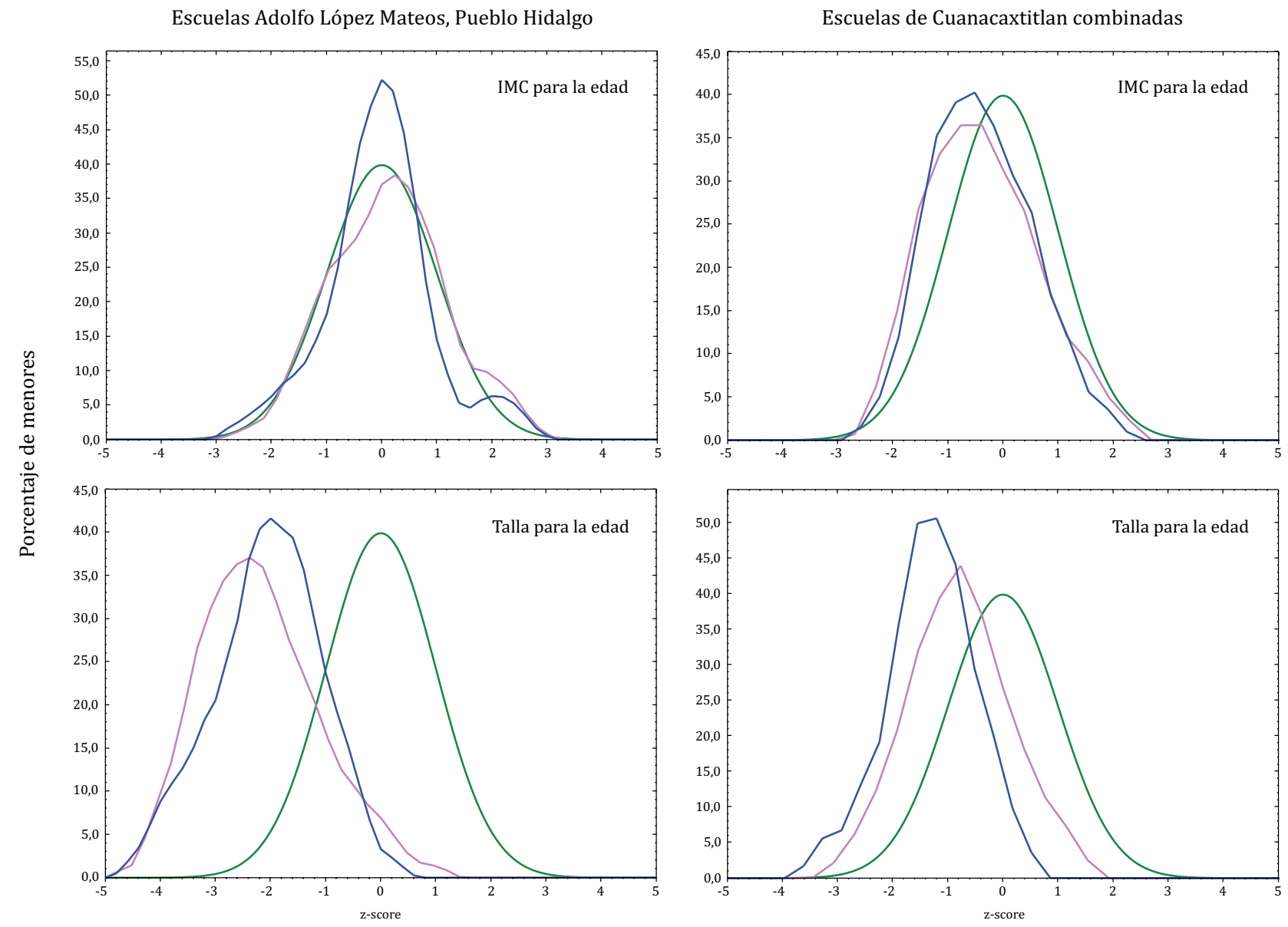

Estándar Organización Mundial de la Salud

Femenino Masculino

Figura 3. Índice de masa corporal y talla para la edad en niños de quinto grado, Escuela Adolfo López Mateos, Pueblo Hidalgo, Guerrero; y de dos escuelas de Cuanacaxtitlán, Guerrero, combinadas. México, 2015.

Fuente: Elaboración propia. 
-0,41 para la escuela Vicente Guerrero, en contraste con una población con estado nutricional "ideal", en la que el z-score promedio, por definición, sería 0 . En cambio, sí se registraron niños con sobrepeso (IMC para la edad con z-score $>1$ ): el $7 \%$ en la escuela Patria y el $8 \%$ en la Vicente Guerrero.

En cambio, entre los niños de $5^{\circ}$ grado de la escuela Adolfo López Mateos, de Pueblo Hidalgo, la prevalencia de desnutrición crónica (talla baja para la edad) fue del 56\%, de los cuales el $19 \%$ presentó talla muy baja para la edad (z-score <-3) una media con z-score de -2,12 (desviación estándar 0,96). Adicionalmente, 3 menores ( $3 \%$ ) -dos niños y una niña- presentaron desnutrición aguda moderada (IMC para la edad con z-score $<-2$ ), mientras que un $8 \%$ de ellos presentó sobrepeso y un $3 \%$ adicional, obesidad, lo que se refleja como una alta frecuencia de los z-scores más elevados (Figura 3).

El análisis de varianza muestra que existen diferencias significativas entre las tres escuelas en cuanto a la media de zscores, tanto de IMC para la edad como de talla para la edad. El análisis de contrastes revela que esta significancia se debe a la diferencia entre las dos comunidades, y no a las existentes entre las escuelas Vicente Guerrero y Patria de Cuanacaxtitlán. Sin embargo, es notorio que la media de z-scores de talla para la edad es significativamente menor $(p<0,01)$ en Pueblo Hidalgo que en Cuanacaxtitlán; mientras que la media de zscores de IMC para la edad es significativamente mayor $(p<0,05)$ en Pueblo Hidalgo que en Cuanacaxtitlán. Es decir, Pueblo Hidalgo tiene mayores tasas de desnutrición crónica que Cuanacaxtitlán, mientras que, en promedio, su estado de nutrición aguda es ligeramente mejor, hecho que se explora con más detalle a continuación. Debido a la falta de diferencias significativas entre las escuelas Vicente Guerrero y Patria, para los análisis subsecuentes se agruparon los datos de ambas. En la Figura 3 se muestran también las gráficas resultantes de dicha combinación.

Posteriormente, se utilizaron pruebas de $t$ para realizar comparaciones entre niñas y niños en ambas comunidades. Dichas pruebas mostraron que tanto niños como niñas tienen promedios significativamente menores $(p<0,05)$ tanto de IMC como de talla para la edad que una población ideal (con distribución estándar de z-scores). La excepción fue el grupo de niñas de Pueblo Hidalgo, cuya media de IMC para edad $(0,22)$ se encontró dentro de la distribución normal estándar. La comparación directa entre niñas y niños en ambas comunidades mostró que, en Pueblo Hidalgo, las niñas tienen un promedio de IMC para edad significativamente mayor ( $p<0,05)$ que los niños; mientras que, en Cuanacaxtitlán, las niñas tienen un promedio de talla para edad significativamente mayor $(p<0,05)$ que los niños.

Finalmente, se probó la hipótesis de que la diferencia de medias de z-score en IMC para la edad, entre ambas comunidades, mayor para Pueblo Hidalgo respecto de Cuanacaxtitlán, pudiera deberse a que la primera tiene mayores porcentajes de menores con desnutrición aguda y con sobrepeso/obesidad. Para ello, se realizaron pruebas de $\chi^{2}$ y prueba de Moses de reacciones extremas; sin embargo, en ambos casos la diferencia de prevalencias no resultó significativa $(p>0,05)$, lo que podría atribuirse al tamaño reducido de la muestra. En cambio, las pruebas de $\chi^{2}$ confirmaron que la prevalencia de talla baja es significativamente mayor a lo esperado en ambas comunidades $(p<0,01)$.

\section{DISCUSIÓN}

\section{Análisis de los programas de atención a la desnutrición}

El diseño de una política pública de la magnitud y trascendencia del programa federal de atención nutricional debiera partir de un diagnóstico de las deficiencias nutricionales en la población atendida, incluso para otorgar suplementos según estas necesidades, aunque se trate de una medida paliativa temporal que no aborda los determinantes estructurales. Tal proceso parece haberse pasado por alto. 
Por el contrario, analizando los datos de la Encuesta Nacional de Salud y Nutrición 2012, Mundo Rosas et al. encuentran que los niños de 2 a 5 años de las familias ubicadas en las categorías inseguridad alimentaria moderada e inseguridad alimentaria severa (destinatarios en principio de los programas) presentan una deficiencia principalmente calórica, mientras que los requerimientos de micronutrientes -a excepción de la Vitamina D- están, en promedio, cubiertos $^{(49)}$.

Como se comentó, más del $60 \%$ de los menores que cumplen criterios para ingresar a la estrategia CAES aplicada en la jurisdicción son niños/as de 2 a 5 años con peso bajo para la talla (desnutrición aguda). A pesar de que las encuestas muestran que dichos niños presentan una deficiencia principalmente calórica, reciben un suplemento exclusivamente vitamínico. Así, no debiera sorprendernos que los niños a quienes les falta comida -quienes sufren hambre crónica- "no crezcan" a pesar de recibir más vitaminas, por más supervisado que sea su consumo, hecho que denota la inadecuación técnica de los programas. Si se considera que el saber hegemónico técnico-científico proveniente de las ciencias de la nutrición es utilizado para criticar y desplazar los saberes locales, es particularmente relevante para el ámbito oficial que los esquemas que genera no se constituyan ellos mismos como objetos de crítica. Esto remite al papel que juega la monocultura del saber y del rigor del saber como uno de los modos más poderosos de producción de no existencia, en términos de Santos ${ }^{(50)}$.

La tendencia a eliminar indicadores de talla baja de los parámetros de desnutrición equivale a invisibilizar la desnutrición o el hambre crónicos, el principal problema de carencia nutricional en Guerrero y el país ${ }^{(9)}$, corroborado en los datos somatométricos de este trabajo. Ello denota la producción activa de no existencia de poblaciones y problemáticas, usando nuevamente los términos de Santos, para quien dicho proceso ocurre "siempre que una entidad dada es descalificada y tornada invisible, ininteligible o descartable de un modo irreversible" ${ }^{\prime(50)}$.
Adicionalmente, la introducción de una importante gama de productos procesados como insumos básicos, obtenibles mediante la "Cruzada Nacional Contra el Hambre" constituye una afrenta hacia las culturas alimentarias locales, no solo en el municipio en cuestión sino a nivel nacional, como han documentado, entre otros, Arana y Cabada ${ }^{(12)}$. Además, tal política no solo tiene poco impacto sobre la prevalencia de la desnutrición, sino que contribuye a la epidemia actual de obesidad, diabetes y otras enfermedades crónicas ${ }^{(51)}$. En la región en cuestión, Ponce ha documentado que la disponibilidad de productos "chatarra" va en aumento, mientras disminuye la de alimentos frescos ${ }^{(48)}$.

El menosprecio biomédico de los saberes alimentarios locales no es un rasgo aislado ni contingente: se inscribe en el marco de las relaciones de colonialidad, caracterizadas por la jerarquización impuesta y naturalizada de seres humanos, saberes, lugares y subjetividades ${ }^{(42)}$; en ese sentido, la colonialidad constituye un dispositivo patogénico estructural ${ }^{(52)}$, recurriendo al término propuesto por Bibeau ${ }^{(31)}$, dispositivo determinante, a su vez, en los itinerarios de desatención expuestos, del cual son expresión. Abonando al papel ya señalado de la monocultura del saber y del rigor del saber como generadores de no existencia ${ }^{(50)}$, las narrativas presentadas muestran el menosprecio institucional hacia la cultura alimentaria local: por un lado, la publicidad oficial anuncia que, en las cocinas "comunitarias" del programa asistencialista referido, el ejército está "enseñando a las campesinas a cocinar"(53,54); y, por otro, se observa la internalización de ese menosprecio incluso por parte de algunas "vocales" del programa PROSPERA que son integrantes de la propia comunidad elegidas para coordinar sus acciones en el nivel de base.

\section{De las narrativas a los itinerarios de desatención nutricional}

El análisis de las narrativas locales sobre malnutrición revela elementos comunes críticos de la carrera del enfermo. Sin embargo, 


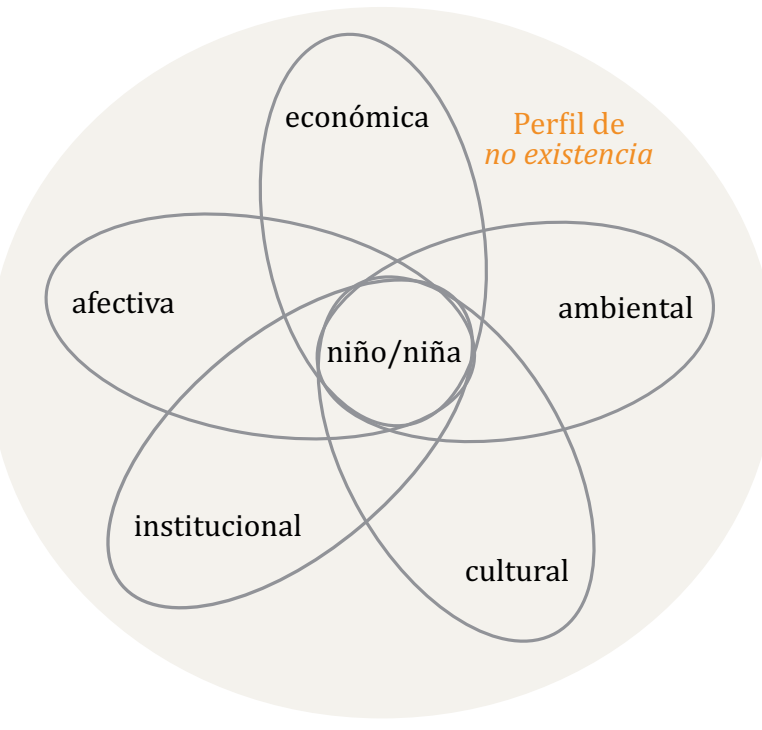

Figura 4. Dimensiones de desatención.

Fuente: Elaboración propia.

cuando el análisis se focaliza en la comprensión de los daños evitables a la salud, resulta imperativo dirigir la mirada, no hacia las decisiones individuales en esta trayectoria, sino hacia los procesos de desatención invisibilizados, caracterizables en sus diversas dimensiones y escalas en la "sociología de las ausencias y de las emergencias" señalada por Santos ${ }^{(50)}$.
Al analizar las narrativas bajo esta óptica emergen, en efecto, distintas dimensiones de la desatención: económica, ambiental, cultural, afectivo-emocional e institucional, las cuales se entretejen y potencializan en formas específicas en un sujeto particular, que redunda en el daño evitable, en este caso nutricional (Figura 4).

El círculo más externo de la Figura 4, que delimita dichas dimensiones, corresponde a un determinado perfil de no existencia, que preside las dimensiones de desatención en su peso diferencial.

También son destacables distintas escalas de desatención, a través de las cuales entendemos que la desatención no solo ocurre a nivel individual, sino que involucra de manera diferencial al núcleo familiar y su ámbito doméstico, al ámbito comunitario, estatal $y$, finalmente, al estructural, que abarca a niños y niñas de manera progresiva y articulada (Figura 5). Esto quiere decir que la desatención es resultado y, a la vez, un mecanismo por el cual sujetos, familias, comunidades y colectividades son eliminados del panorama, ausentados, descalificados y tornados desechables.

Al igual que en la Figura 4, el perfil de no existencia refleja la especificidad relacional de las escalas de desatención. Y ello pone a su vez de relieve el territorio, en toda

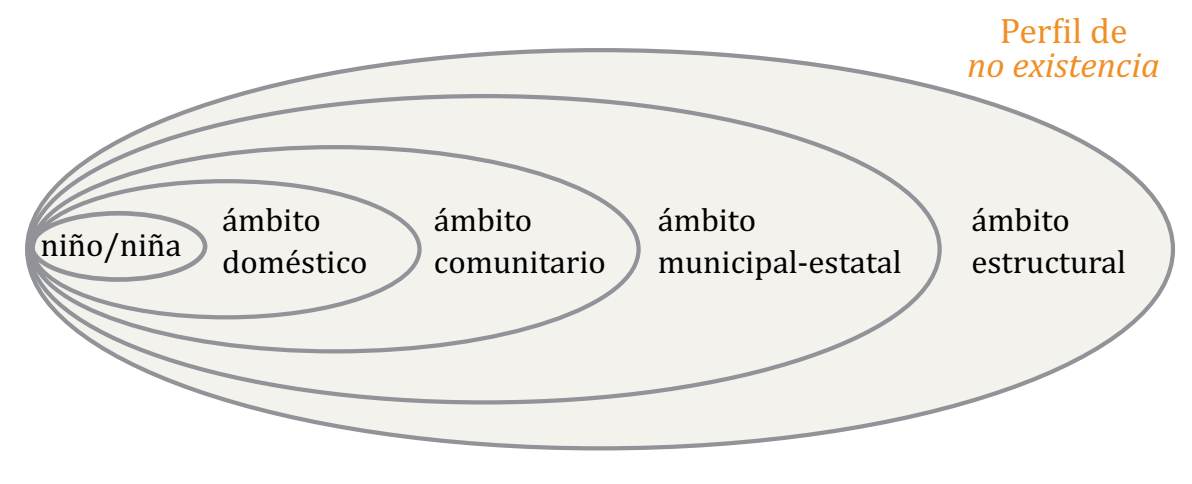

Figura 5. Escalas de desatención.

Fuente: Elaboración propia. 
su complejidad, como referente en el que se desarrollan los itinerarios de desatención nutricional.

Como uno de los elementos de peso diferencial en los perfiles de no existencia, la desatención económica se refleja en la persistente precariedad material, constante en los itinerarios analizados, con impacto significativo en la dieta y el estado nutricional de los sujetos y grupos. Ello ejemplifica cómo la desatención ocurre en distintas escalas dentro de una dimensión específica, pues la pobreza vivida por las comunidades indígenas no se da en un vacío, ni resulta de causas "naturales": tiene profundas raíces sociales e históricas. Como explica Bartra, a nivel nacional "el campo ha sido minimizado, invisibilizado, reducido, redimensionado a la baja y mal atendido"(55).

En ese sentido, la capacidad de las familias campesinas para obtener alimentos suficientes, cuantitativa y cualitativamente, está directamente ligada al acceso a la tierra, al tipo de tenencia, al rendimiento agrícola y al entorno ecológico que permite o impide complementar la dieta con diversas especies vegetales y animales silvestres en las denominadas "redes de seguridad" (safety nets) propias de las economías campesinas que practican la recolección estacional de alimentos ${ }^{(56,57,58,59)}$. Sin embargo, para la zona que nos ocupa y de acuerdo con testimonios recabados, esta fuente alimentaria se encuentra también vulnerada, ante la sinergia económica y ambiental de la desatención.

La vulnerabilidad del entorno ecológico resulta crítica para los itinerarios de atención o desatención nutricional, cobrando mayor relevancia ante la amenaza que vive la región por la instauración de megaproyectos como los mineros, que representan un riesgo global de deterioro ambiental ${ }^{(60)}$.

En otra escala, la inadecuación técnica y cultural de los programas oficiales de atención a la desnutrición, tal como se ha analizado, denota desatención institucional, reflejando la confluencia de dimensiones en los itinerarios de desatención.

El soslayo biomédico de la dimensión afectivo-emocional(61) resulta otro factor constitutivo de los itinerarios de desatención. Lo ejemplifica el caso referido de Irene, así como la invisibilización de la violencia doméstica, a pesar de existir normas fijadas por las instituciones sanitarias ${ }^{(62)}$. De hecho, no existe una aproximación integral que reconozca la articulación entre factores como la violencia doméstica o el alcoholismo y la malnutrición; de ahí la necesidad de una perspectiva que incorpore en todo su peso dichos factores, considerando la evolución progresiva del daño, manifiesta en los itinerarios de desatención, en este caso, nutricional.

La invisibilización o el soslayo de la violencia doméstica puede operar, eventualmente, incluso en el marco de las decisiones que toman algunas autoridades tradicionales, cuando "atienden" demandas culpabilizando a las víctimas, como sugiere la narrativa de Lorena, presentada anteriormente.

La violencia doméstica que denotan las narrativas, fenómeno que trasciende el ámbito local ${ }^{(63)}$, ilustra cómo las articulaciones y sinergias entre diferentes dimensiones de la desatención llevan al daño evitable. Es decir, la violencia doméstica puede ser la "gota que derrama el vaso", pero a partir del sustrato de otras dimensiones de desatención que reproducen la inequidad estructural de género, etnia y clase.

\section{Perfiles somatométricos e incorporación}

El ejercicio de somatometría realizado muestra altos índices de desnutrición crónica, particularmente en la comunidad de Pueblo Hidalgo. También sugiere una aparente polarización en el estado agudo de nutrición al detectarse menores en edad escolar con desnutrición aguda y otros con sobrepeso u obesidad, ambos en proporción mayor en la comunidad con mayores índices de desnutrición crónica. Si bien, como se mencionó, el ejercicio fue realizado como parte de un taller en diálogo con las comunidades, y no pretende un diseño muestral representativo, los resultados son coherentes con múltiples investigaciones al respecto ${ }^{(10,27,64,65,66,67)}$. 
Estos resultados forman parte de la impronta física de los itinerarios de desatención vividos por los sujetos ${ }^{(66)}$. Desde esta perspectiva, el concepto de itinerario de desatención se complementa con el de vías de incorporación (pathways of embodiment) ${ }^{(68,69)}$, focalizando así los procesos invisibilizados de desatención. El concepto de embodiment, traducido de diversas maneras (incorporación, encarnación, corporización), refiere a "la forma en que incorporamos, biológicamente, el mundo material y social en que vivimos, desde in utero hasta la muerte" ${ }^{\prime \prime 68)}$. Ya Fassin lo afirma: la desigualdad social se inscribe en los cuerpos ${ }^{(70)}$.

Es decir, las trayectorias por las que atraviesan los sujetos, así como las múltiples dimensiones y escalas en que son desatendidos, no son abstracciones: se manifiestan en algo tan concreto como el peso y la talla. Estos perfiles somatométricos desiguales son la concreción de múltiples inequidades subyacentes ${ }^{(71)}$.

\section{CONCLUSIONES}

Como hemos visto, para que un niño o niña llegue a sufrir de un estado de desnutrición aguda o crónica, necesita transitar por una serie de oportunidades perdidas de atención nutricional, a través de dinámicas de desatención distribuidas diferencialmente

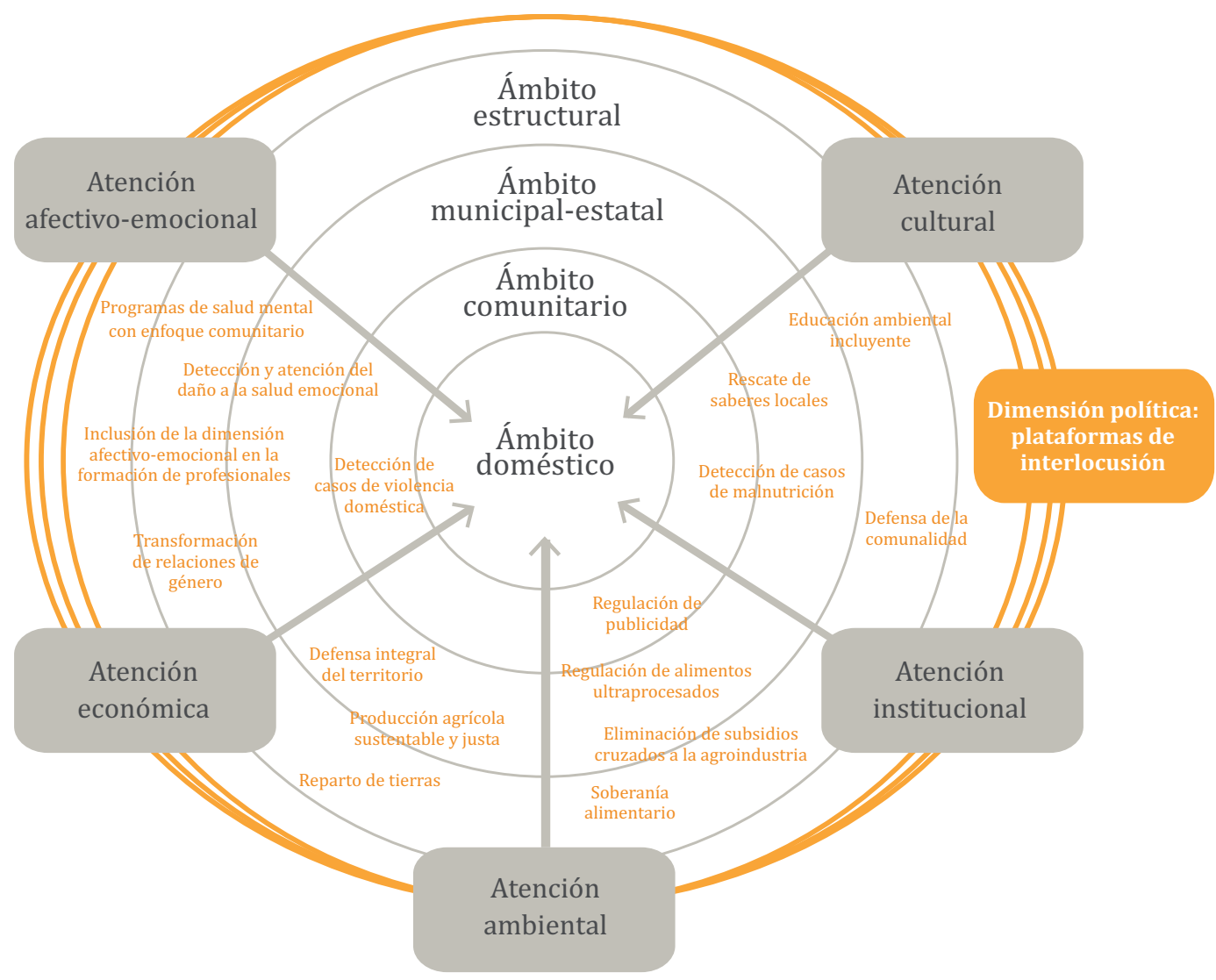

Figura 6. Ejemplo del ordenamiento no exhaustivo de dimensiones y escalas, como matriz de análisis de un itinerario de atención nutricional.

Fuente: Elaboración propia. 
en la población. Hemos denominado al paso por estos diversos escenarios itinerarios de desatención nutricional, ya que nos parece un concepto pertinente para analizar causas articuladas de desigualdad y exclusión en salud generadoras de daños evitables en un proceso envolvente y evolutivo.

En ese sentido, son destacables en dichos itinerarios sus diversas escalas (individual, familiar, comunitaria, estatal, estructural) y dimensiones (económica, ambiental, cultural, afectivo-emocional, institucional). Lo fundamental en este análisis es comprender la sinergia existente entre escalas, entre dimensiones, y entre escalas y dimensiones. El reconocimiento de esta sinergia puede derivar en procedimientos y herramientas operativas de detección y seguimiento que destaquen esas articulaciones y su contexto.

El concepto de itinerarios de desatención tiene un alcance analítico y un alcance operativo. En el primero, reconociendo la responsabilidad del Estado - no exclusiva pero sí determinante- en la conformación de los itinerarios de desatención nutricional, en tanto no se focalicen y aborden los mecanismos contextuales productores de no existencia que generan dichos itinerarios, persistirá la perspectiva técnicamente atomizada e ineficaz y conceptualmente monológica y excluyente, sintomática y reduccionista que subyace en su conformación. Sin embargo, las recomendaciones inmediatas no pueden esperar: simplemente derivan del reconocimiento de las diversas dimensiones y escalas involucradas en dichos itinerarios y de su sinergia patogénica, contraponiendo a ello una estrategia que las ubique y pondere bajo una perspectiva incluyente, pues en cada una de las escalas operan las mismas dimensiones, pero de una manera particular. Un ejemplo no exhaustivo de este ordenamiento de dimensiones y escalas se presenta en la Figura 6, reconociendo la relevancia de la dimensión política mediada por la existencia de plataformas de interlocución referidas en este trabajo.

En términos operativos, el concepto de itinerario de desatención nutricional permite visibilizar las diferentes necesidades específicas de atención de cada sujeto y sus entornos, y fijar como un objetivo integrador el convertir itinerarios de desatención en itinerarios de atención. En ese sentido, también permite identificar y reconocer aquellas dimensiones que van más allá de una lectura que reduce el origen del proceso al orden de los comportamientos individuales y familiares, al poner en evidencia la sinergia entre dimensiones y escalas.

Ello implicaría, a su vez, generar registros de seguimiento que integren parámetros cualitativos, ambientales y relacionales; la Figura 4 y la Figura 5 pueden servir como referencia al destacar las dimensiones o escalas particulares cuya afectación puede consignarse y seguirse en los itinerarios.

Los itinerarios de desatención nutricional constituyen, a su vez, insumos inmediatos de reflexión en procesos organizativos y en el seno de movimientos sociales, porque ponen de relieve la concreción de los procesos de daño evitable en casos específicos, desagregables en sus diversas escalas y dimensiones sobre las que pueden incidir los propios movimientos y comunidades, y también orientan la organización para la exigencia de derechos y transformaciones estructurales de las relaciones de poder generadoras de desatención.

Así como los itinerarios de desatención involucran múltiples escalas y dimensiones, su transformación en itinerarios de atención requiere involucrar distintas instancias en sus correspondientes niveles, así como a diversos actores. Aunque la desatención opera también en circuitos no formales, la actuación del personal operativo institucional, especialmente en el medio rural, resulta determinante a nivel individual, doméstico y comunitario, y su papel puede potenciarse si se focaliza a la desatención nutricional y sus itinerarios como referentes.

La conversión de itinerarios de desatención en itinerarios de atención obliga a la participación dialógica en todos los niveles, partiendo de las comunidades e incluyendo en otra escala a las diversas instancias de gobierno y los encargados de la política económica, agroalimentaria o ambiental. La formulación e implementación de políticas públicas eficaces requiere el concurso de una 
diversidad de actores sociales en genuinos procesos de participación social ${ }^{(72)}$. Sin embargo, la concreción a menudo pendiente de dicha participación, requiere generar plataformas de interlocución en el seno de los movimientos sociales, de los procesos autonómicos y de las instancias locales de gestión y de toma de decisiones, que en el marco de los pueblos originarios tienen en la comunalidad un referente esencial ${ }^{(73)}$. Se trata de la potencialización de las regidurías municipales de salud, de la instauración de comisiones municipales de salud incluyentes y deliberativas, pero también del involucramiento de comisariados y comisarios ejidales y de bienes comunales, dado el arraigo y legitimidad de las estructuras agrarias colectivas en muchas comunidades rurales ${ }^{(8,26,28,52)}$.

Ahí donde se prescinde en los hechos del bien común como referente esencial de gobierno, es evidente que el Estado coadyuva en la producción de no existencia y, como parte de ello, no explora ni reconoce la existencia de itinerarios de desatención ni de sus diversas dimensiones y escalas, y lo hará solo reactivamente y bajo la interlocución, supervisión o presión de instancias concretas de una genuina participación social que precisamente, de serlo, le resulta subversiva por naturaleza ${ }^{(74)}$. Sin ella, no regulará los alimentos ultraprocesados ajenos a una buena alimentación, ni adecuará sus programas y esquemas institucionales; tampoco diseñará ni articulará sus políticas públicas tomando en cuenta el carácter evolutivo y dinámico de dichos itinerarios. Por tanto, la producción de no existencia que se expresa en la distribución diferencial de itinerarios de desatención nutricional y se traduce en determinados perfiles que, a su vez, al reiterarse, derivan en patrones de no existencia, ha de ser puesta de relieve y sustituida mediante la emergencia de itinerarios de atención en sus diversas dimensiones y escalas.

Una clave para incidir en la génesis de los itinerarios de desatención nutricional radica en instrumentar procesos de genuina participación social que, ciertamente, la retórica no resuelve. La adscripción orgánica de profesionales con una perspectiva y una práctica incluyente en términos de salud colectiva a procesos y movimientos sociales puede favorecer dichos procesos, pero solamente a partir de plataformas de interlocución radicadas en las dinámicas e instancias de gestión local y regional que, en el caso de los pueblos originarios, se ubican a menudo en la cultura de la comunalidad y en los procesos autonómicos que de ella pueden derivar.

\section{AGRADECIMIENTOS}

Agradecemos el apoyo del Instituto de Nutrición y Salud Kellogg's a través del proyecto "Potencial de los saberes y recursos locales para mejorar la nutrición en comunidades indígenas de la región Costa Chica-Montaña de Guerrero. Propuestas de acción desde una instancia organizativa comunitaria regional", folio 13707. Agradecemos la colaboración de los entrevistados, de la Comisión de Salud y
Autoridades de la CRAC-PC, en particular de las compañeras Catalina Carreño y Teresa Guerrero, así como de Berenice Rodríguez, Zuri Samuel Vera y Ana Catalina Sedano (ASFM-INAH), del personal docente de las escuelas primarias Patria y Vicente Guerrero de Cuanacaxtitlán y Adolfo López Mateos de Pueblo Hidalgo, de la jurisdicción sanitaria 06 de Ometepec, y de Silvia Alatorre por su apoyo en el análisis estadístico, y los pertinentes comentarios de las/os revisoras/es anónimas/os. 


\section{REFERENCIAS BIBLIOGRÁFICAS}

1. Laurell AC. La salud-enfermedad como proceso social. Cuadernos Médico Sociales. 1982;(19):1-11.

2. Menéndez EL. Epidemiología sociocultural: propuestas y posibilidades. Región y Sociedad. 2008;20(Esp 2):5-50.

3. Menéndez EL. Modelos de atención de los padecimientos: de exclusiones teóricas y articulaciones prácticas. Ciência \& Saúde Coletiva. 2003;8(1):185-207.

4. Hersch-Martínez P. Epidemiología sociocultural: una perspectiva necesaria. Salud Pública de México. 2013;55(5):512-518.

5. Krieger N. Epidemiology and the web of causation: Has anyone seen the spider? Social Science and Medicine. 1994;39(7):887-903.

6. Breilh J. La epidemiología crítica: una nueva forma de mirar la salud en el espacio urbano. Salud Colectiva. 2010;6(1):83-101.

7. Breilh J. La determinación social de la salud como herramienta de transformación hacia una nueva salud pública (salud colectiva). Revista Facultad Nacional de Salud Pública. 2013;31(Supl 1):S13-S27.

8. Hersch-Martínez P, González-Chévez L, Sedano-Díaz AC. Epidemiología sociocultural: referente operativo en el estudio de los saberes locales relacionados con la salud-enfermedad y la atención-desatención, una experiencia aplicada en dos municipios de Oaxaca y Guerrero, México. En: Actas del Congreso ISE XIII [Internet]. MontpeIlier; 2012 [citado 10 mar 2016]. Disponible en: https://goo.gl/AQGeW1.

9. Instituto Nacional de Salud Pública. Desnutrición en México: intervenciones hacia su erradicación [Internet]. 2012 [citado 30 mar 2016]. Disponible en: https://goo.gl/ek9306.

10. González-de-Cossío T, Rivera JA, GonzálezCastell D, Unar-Munguía M, Monterrubio EA. Child malnutrition in Mexico in the last two decades: prevalence using the new WHO 2006 growth standards. Salud Pública de México. 2009;51(Supl 4):S494-S506.

11. Popkin BM. Nutrition, agriculture and the global food system in low and middle income countries. Food Policy. 2014;47:91-96.

12. Arana Cedeño M, Cabada X. Nutrition policies taken hostage by multinationals and conflicts of interest: The obesity and diabetes epidemic in
Mexico. In: Right to Food and Nutrition Watch [Internet]. Berlin; 2015 [citado 30 mar 2016]. p. 70-71. Disponible en: https://goo.gl/OdXFda.

13. GRAIN. Free trade and Mexico's junk food epidemic [Internet]. Barcelona; 2015 [citado 30 mar 2016]. Disponible en: https://goo.gl/Xy6pTA.

14. Hernández-Ávila M, Gutiérrez JP, ReynosoNoverón N. Diabetes mellitus en México: El estado de la epidemia. Salud Pública de México. 2013;55(Supl 2):S129-S36.

15. Stern D, Piernas C, Barquera S, Rivera JA, Popkin BM. Caloric beverages were major sources of energy among children and adults in Mexico, 1999-2012. Journal of Nutrition. 2014;144(6):949-956.

16. Carmona-Fonseca J, Correa BAM. Determinación social de la desnutrición y el retardo sicomotor en preescolares de Urabá (Colombia): Un análisis con la Epidemiología Crítica. Revista Facultad Nacional de Salud Pública. 2014;32(1):40-51.

17. Goffman E. Internados: Ensayos sobre la situación social de los enfermos mentales. 2a ed. Buenos Aires: Amorrortu; 1972.

18. Kleinman A. The illness narratives: suffering, healing and the human condition. New York: Basic Books; 1988.

19. Werner JF, Benoist J. D'un itinéraire à l'autre ou les incertitudes du savoir ethnographique. En: Soigner au pluriel: Essais sur le pluralisme médical. Paris: Karthala; 1996. p. 363-392.

20. Twaddle AC. Sickness and the sickness career: some implications. In: The relevance of social science for medicine. Dordrecht: Reidel; 1981. p. 111-1333.

21. Pescosolido B. Illness career and network ties: A conceptual model of utilization and compliance. In: Albrecht G, Levy J, (ed.). Advances in medical sociology. Greenwich, Connecticut: JAI Press; 1991. p. 161-184.

22. Serra J, Brenes C. Recuperación crítica de indicadores socioeconómicos: La experiencia del Programa de Salud Comunitaria Hospital sin $\mathrm{Pa}$ redes. En: Rojas-Aravena F, (ed.). Centroamérica: Indicadores socioeconómicos para el desarrollo. San José: FLACSO; 1983. p. 269-303.

23. Núñez-Urquiza RM. Utilización del método de detección de eslabones críticos en los sistemas de atención de la salud para evitar las muertes maternas. En: Estado mundial de la infancia 2009: Salud materna y neonatal. Ginebra: UNICEF; 2009. 
24. Vargas Escamilla BF, Campos Navarro R. Trayectoria de atención, desatención y denuncia en un caso de mortalidad materna: perspectiva localglobal. Revista CONAMED. 2015;20(4):174-181.

25. González-Chévez L. La policía comunitaria en Guerrero: Luchas decoloniales, nuevos desafíos para la CRAC-Policía Comunitaria de Guerrero. Pacarina del Sur. 2014;5(20):e972.

26. Hersch-Martínez P, Sedano-Díaz AC. Las comisiones de salud como espacios dialógicos de relevancia para la epidemiología sociocultural: Ejemplos de caso en comunidades de Guerrero y Oaxaca. Oxtotitlán. 2013;7:5-13.

27. Balbuena-Ramírez J. Mujer, desnutrición y pobreza: Estudio en dos comunidades de la Montaña de Guerrero. Puebla: Colegio de Posgraduados; 2011.

28. Hersch-Martínez, P. Diálogo de saberes; ¿para qué?, ¿para quién?: Algunas experiencias desde el programa de investigación Actores Sociales de la Flora Medicinal en México, del Instituto Nacional de Antropología e Historia. En: Argueta A, Corona E, Hersch P, (eds.). Saberes colectivos y diálogo de saberes en México. México: UNAM; 2011. p. 177-200.

29. Almeida-Filho N. Complejidad y transdisciplinariedad en el campo de la salud colectiva: evaluación de conceptos y aplicaciones. Salud Colectiva. 2006;2(2):123-146.

30. Rosenfield PL. The potential of transdisciplinary research for sustaining and extending linkages between the health and social sciences. Social Science \& Medicine. 1992;35(11):1343-1357.

31. Bibeau G. ¿Hay una enfermedad en Las Américas?: Otro camino de la antropología médica para nuestro tiempo. En: Cultura y salud en la construcción de Las Américas: Reflexiones sobre el sujeto social. Bogotá: Instituto Colombiano de Cultura, Instituto Colombiano de Antropología, Comitato Internazionale per lo Svilupo dei Popoli; 1992.

32. World Health Organization. WHO Child Growth Standards. Geneva: WHO; 2006.

33. World Health Organization. Growth reference 5-19 years. Ginebra: WHO; 2007.

34. Martínez-Salgado C. El muestreo en investigación cualitativa: Principios básicos y algunas controversias. Ciência \& Saúde Coletiva. 2012;17(3):613-619.

35. Secretaría de Desarrollo Social. Reglas de operación de PROSPERA Programa de Inclusión Social, para el ejercicio fiscal 2015. México: SEDESOL; 2015.

36. Sandoval B. Tensiones entre la condicionalidad del Oportunidades y las ideas de responsabilidad y reciprocidad que le subyacen. Estudios Sociológicos. 2015;33(97):3-29.

37. Los números de la cruzada contra el hambre. Milenio Datalab [Internet]. 7 mar 2016 [citado 10 mar 2016]. Disponible en: https://goo.gl/PPhU4o.

38. Midaglia C. Un balance crítico de los programas sociales en América Latina: Entre el liberalismo y el retorno del Estado. Nueva Sociedad. 2012;(239):79-89.

39. Tanaka M, Trivelli C. Las trampas de la focalización y la participación: Pobreza y políticas sociales en el Perú durante la década de Fujimori. Lima: Instituto de Estudios Peruanos; 2002.

40. Rodríguez-Manzanares E, Rodríguez-Peñaloza M. El Programa de Desarrollo Humano "Oportunidades: contigo es posible": ¿Política económica versus política social? Espacios Públicos. 2007;10(20):162-185.

41. Gómez de Silva G. Beneficio: Breve diccionario etimológico de la lengua española. México: Fondo de Cultura Económica; 1989. p. 108.

42. Restrepo E, Rojas A. Inflexión decolonial: fuentes, conceptos y cuestionamientos. Popayán: Universidad del Cauca; 2010.

43. Secretaría de Salud. Manual para el suministro y control del suplemento alimenticio [Internet]. 2014 [citado 12 mar 2016]. Disponible en: http:// tinyurl.com/hldsnd8.

44. Secretaría de Salud. Manual de procedimientos para la correcta implementación de la estrategia CAES (Complementos Alimenticios Estrictamente Supervisados). México: Secretaría de Salud; 2015.

45. Estado de Guerrero. Estadísticas de estado nutricional de niños menores de 5 años. Guerrero: Sistema de Información en Salud; 2015.

46. Fierro-Álvarez A, González-López MM. Las tecnologías locales usadas en el cultivo del maíz en San Luis Acatlán. En: VII Mesa Redonda El conocimiento antropológico e histórico sobre Guerrero. Chilpancingo, Guerrero: INAH; 2016.

47. BarreraJF, AvelinoJ, Huerta G, HerreraJ, Gómez J. La roya del café: crónica de una devastación anunciada. Ecofronteras. 2013;49(3):22-25.

48. Ponce J. Situación alimentaria: Resumen. En: Rescatar nuestras raíces, afirmar nuestra identidad 
[Internet]. 2011 [citado 10 mar 2016]. Disponible en: http://tinyurl.com/z8m9ha7.

49. Mundo-Rosas V, Cruz-Góngora V, JiménezAguilar A, Shamah-Levy T. Diversidad de la dieta y consumo de nutrimentos en niños de 24 a 59 meses de edad y su asociación con inseguridad alimentaria. Salud Pública de México. 2014;56(Supl 1):S39-S46

50. Santos de Sousa B. El milenio huérfano: Ensayos para una nueva cultura política. Madrid: Trotta; 2005.

51. Enciso-Landero A. Causan sobrepeso alimentos de comedores comunitarios. La Jornada [Internet]. 2 feb 2016 [citado 1 abr 2016]. Disponible en: http://tinyurl.com/zzxhgb5.

52. Hersch-Martínez P. Algunos elementos epistémicos, metodológicos y políticos en torno a las propuestas actuales de "salud intercultural". Ponencia presentada en IV Congreso Colombiano de Etnobiología; oct 2013; Bogotá, Colombia.

53. Noticieros Televisa. Apoyan a cocineras de comedores comunitarios [Internet]. 2014 [citado 1 sep 2016]. Disponible en: http://tinyurl.com/jmbcyyp.

54. Secretaría de Marina Armada de México. Sin Hambre México Prospera [Internet]. 2015 [citado 1 sep 2016]. Disponible en: http://tinyurl.com/ j8udkhg.

55. Bartra A. Mesa final. En: FONAM 2012: Elementos sustantivos para la construcción de una política pública alimentaria y nutricional en México [Internet]. 2012 [citado 10 mar 2016]. Disponible en: http://tinyurl.com/hvugvak.

56. Mavengahama S, McLachlan M, de Clercq W. The role of wild vegetable species in household food security in maize based subsistence cropping systems. Food Security. 2013;5(2):227-233.

57. Shumsky SA, Hickey GM, Pelletier B, Johns $T$. Understanding the contribution of wild edible plants to rural social-ecological resilience in semi-arid Kenya. Ecology and Society. 2014;19(4):34.

58. González-Chévez L, Hersch-Martínez P. Alimentación y cultura nahuas de Guerrero. Cuernavaca: Instituto Nacional de Antropología e Historia, Secretaría de Salud del Estado de Guerrero; 2005.

59. Hersch-Martínez P, González-Chévez L, Glass R. Survival strategies that involve wild species in Northern Guerrero, Mexico: A proposal for enhancing a safety net system. In: Proceedings Rural Livelihoods, Forests and Biodiversity. Bonn: CIFOR; 2003.
60. González-Chévez L. Panorama minero en Guerrero y resistencia indígena. El Tlacuache [Internet]. 2011;(459):1-3 [citado 12 mar 2016]. Disponible en: http://tinyurl.com/jfotb27.

61. Sedano-Díaz AC, Hersch-Martínez P. El soslayo de la dimensión emocional-afectiva en la salud pública: Algunas narrativas en Guerrero. En: VI Mesa Redonda El conocimiento antropológico e histórico sobre Guerrero: Avances en su investigación y su relación con las regiones vecinas. Taxco: INAH; 2014

62. México, Secretaría de Salud. Norma Oficial Mexicana 046-SSA2-2005 Violencia familiar, sexual y contra las mujeres: Criterios para la prevención y atención [Internet]. 2005 [citado 10 mar 2016]. Disponible en: http://tinyurl.com/hs7dklh.

63. Instituto Nacional de Estadística y Geografía. Panorama de violencia contra las mujeres en México. México: INEG; 2013.

64. Cuevas-Nasu L, Rivera-Dommarco JA, Shamah-Levy T, Mundo-Rosas V, Méndez-Gómez Humarán I. Inseguridad alimentaria y estado de nutrición en menores de cinco años de edad en México. Salud Pública de México. 2014;56(Supl. 1):S47-S53.

65. González-Guzmán R, García-García JJ, Tinoco-Marquina A. La inequidad por clase, etnia y género expresada en el desmedro. Revista Gerencia y Políticas de Salud [Internet]. 2010;9(18) [citado 10 mar 2016]. Disponible en: http://tinyurl. com/gsd7hrf.

66. Pérez-Escamilla R, Villalpando S, Shamah-Levy T, Méndez-Gómez Humarán I. Household food insecurity, diabetes and hypertension among Mexican adults: results from Ensanut 2012. Salud Pública de México. 2014;56(Supl 1):S62-S70.

67. Aguirre P. Ricos flacos y gordos pobres: La alimentación en crisis. Buenos Aires: Capital Intelectual; 2007.

68. Krieger N. A glossary for social epidemiology. Journal of Epidemiology Community \& Community Health. 2001;55(10):693-700.

69. Krieger N. Theories for social epidemiology in the 21st century: an ecosocial perspective. International Journal of Epidemiology. 2001;30(4):668-677.

70. Fassin D. L'espace politique de la santé: Essai de généalogie. Paris: PUF; 1996.

71. López-Arellano O, Blanco Gil J. Desigualdad social e inequidades en salud. Desarrollo de con- 
ceptos y comprensión de relaciones. Salud Problema Nueva Época. 2003;8(4):7-16.

72. Hersch-Martínez P. Participación social en salud: Espacios y actores determinantes en su impulso. Salud Pública de México. 1992;34(6):678-688.

73. Maldonado-Alvarado B. Autonomía y comunalidad india: Enfoques y propuestas desde Oaxaca.
México: Instituto Nacional de Antropología e Historia; 2002.

74. Wolfe A. The limits of legitimacy: Political contradictions in contemporary capitalism. New York: The Free Press; 1977.

\section{FORMA DE CITAR}

Hersch-Martínez P, Pisanty-Alatorre J. Desnutrición crónica en escolares: itinerarios de desatención nutricional y programas oficiales en comunidades indígenas de Guerrero, México. Salud Colectiva. 2016;(12)4:551-573. doi: 10.18294/ sc. 2016.917

Recibido: 2 de abril de 2016 | Versión final: 4 de septiembre de 2016 | Aprobado: 8 de octubre de 2016

\footnotetext{
(c) (1) (\$)

Este obra está bajo una licencia de Creative Commons Reconocimiento-NoComercial 4.0 Internacional. Reconocimiento - Permite copiar, distribuir y comunicar públicamente la obra. A cambio, se debe reconocer y citar al autor original. No Comercial - Esta obra no puede ser utilizada con finalidades comerciales, a menos que se obtenga el permiso.
}

http://dx.doi.org/10.18294/sc.2016.917 